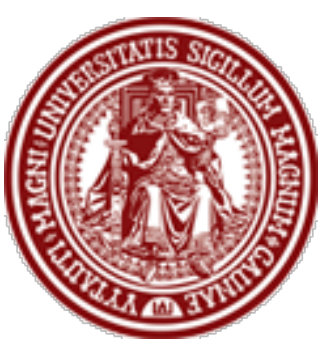

sciendo

\section{BALTIC JOURNAL OF LAW \& POLITICS}

A Journal of Vytautas Magnus University

VOLUME 13, NUMBER 1 (2020)

ISSN 2029-0454

Cit.: Baltic Journal of Law \& Politics 13:1 (2020): 140-162

https://content.sciendo.com/view/journals/bjlp/bjlp-

overview.xml

DOI: $10.2478 /$ bjlp-2020-0006

\title{
BALANCING PERSONAL DATA PROTECTION WITH OTHER HUMAN RIGHTS AND PUBLIC INTEREST: BETWEEN THEORY AND PRACTICE
}

\author{
Viktoras Justickis \\ Professor; Dr. Jur. \\ Mykolas Romeris University, School of Law (Lithuania) \\ Contact information \\ Address: Rūtu 13-2 10310 Vilnius, Lithuania \\ Phone: +37061533289 \\ E-mail address: Justickis1@gmail.com
}

Received: April 26, 2020; reviews: 2; accepted: July 28, 2020.

\section{ABSTRACT}

The role of balancing in the development and application of European data protection is enormous. European courts widely use it; it is the basis for harmonization of pan-European and national laws, plays a crucial role in everyday data protection. Therefore, the correctness of a huge number of critical decisions in the EU depends on the perfection of the balancing method. However, the real ability of the balancing method to cope with this mission has been subjected to intense criticism in the scientific literature. This criticism has highlighted its imperfections and casts doubt on its suitability to optimize the relation between competing rights. Paradoxically, the everyday practice of balancing tends to ignore this criticism. The limitations of the balancing method are typically not discussed and are not taken into account when considering legal cases and solving practical issues. Thus, it is tacitly assumed that the shortcomings and limitations of the balancing method, which the criticism points out, are 
irrelevant when making real-life decisions. This article discusses the scope of this phenomenon, its manifestations, and its impact on the quality of data protection decisions based on the balancing method:sub-optimality of these decisions, their opacity, public dissatisfaction with the legal regulation, its instability and low authority The ways of bridging the gap between the practice of balancing and science and broader consideration by the practice of the shortcomings of the balancing method identified during scientific discussions are considered.

\section{KEYWORDS}

Data protection rights, the conflict of this right with other human rights, balancing method, critics of balancing method, shortcomings of balancing 


\section{INTRODUCTION}

Over the past decades, along with the formation of the information society, the role of the legal protection of personal data has been rapidly growing. EU Charter of Fundamental Rights, The European Convention on Human rights, Council of Europe Convention, and the "EU General Data Protection Regulation (EU-GDPR)" (2016) created an extensive and widely ramified system of the legal protection of personal data. However, the rapidly evolving data protection often interferes with other human civil, economic, and social rights. ${ }^{1}$ The leading role in resolving these contradictions is played by the balancing method. Balancing is a method of resolving such conflicts by establishing their optimal ratio(proportionality). ${ }^{2}$

The role of balancing in the protection of personal data is enormous. It is widely used by European courts to resolve disputes arising in the application of the data protection right ${ }^{3}$. It is also the basis for harmonization of pan-European and national laws; it is used to establish the correct correlation between the interests of the European Union and a member country. It plays a crucial role in everyday data protection. The main legislative act on data protection, the "EU General Data Protection Regulation" establishes that just balancing is supposed to be the primary means of regulating the relationship between the data protection right and other rights. ${ }^{4}$ Its Recital 4 states:

The processing of personal data should be designed to serve mankind. The right to the protection of personal data is not an absolute right; it must be considered in relation to its function in society and be balanced against other fundamental rights, following the principle of proportionality. This Regulation respects all fundamental rights and observes the freedoms and principles recognized in the Charter as enshrined in the Treaties, in particular the respect for private and family life, home and communications, the protection of personal data, freedom of thought, conscience and religion, freedom of expression and information,

\footnotetext{
${ }^{1}$ Denis Kelleher and Karen Murray, EU Data Protection Law (London: Bloomsbury Publishing, 2018), 911; Luka Burazin, "Conflicts Between Fundamental Rights Norms"; in: David Duarte and Jorge Silva Sampaio, eds., Proportionality in Law. An Analytical Perspective (Cham: Springer, 2018).

${ }^{2}$ EDPS Guidelines on assessing the proportionality of measures that limit the fundamental rights to privacy and the protection of personal data, European Data Protection Supervisor (19 December 2019) // https://edps.europa.eu/sites/edp/files/publication/19-12-19_edps_proportionality_guidelines2_en.pdf; Panagiotis Souliotis, "Proportionality And The European Convention On Human Rights: A Critical View" (2016) // https://papers.ssrn.com/sol3/papers.cfm?abstract_id=2690366; Bernard Schlink, "Proportionality": 249; in: Michel Rosenfeld and Andras Sajó, eds., The Oxford Handbook of Comparative Constitutional Law (Oxford: Oxford University Press, 2012).

3 Denis Kelleher and Karen Murray, supra note 1, xi-xviii.

${ }^{4}$ Regulation (EU) 2016/679 of the European Parliament and of the Council of 27 April 2016 on the protection of natural persons concerning the processing of personal data and on the free movement of such data, and repealing Directive 95/46/EC (General Data Protection Regulation) EU General Data Protection Regulation (EU-GDPR), Official Journal of the European Union (2016 L 119/1).
} 
freedom to conduct a business, the right to an effective remedy and to a fair trial, and cultural, religious and linguistic diversity. ${ }^{5}$

A significant number of the "EU General Data Protection Regulation" articles directly indicate the need to establish a proper proportion between the protection of personal data and other values (See: Articles 6(3), 6(4), $9(2 \mathrm{~g}), 9(2 \mathrm{j}), 9(2 \mathrm{i}), 9(2 \mathrm{j})$, $14,19,23,24(2), 34(3 c), 35(7 b), 83(1), 83(9), 84(1), 90(1)$; recitals 4,19, 49, $50,62,73,129,148,151,152,156,170){ }^{6}$

Of fundamental importance was the publication in 2019 of the draft of "EDPS Guidelines on assessing the proportionality of measures that limit the fundamental rights to privacy and to the protection of personal data"7. This document qualifies the balancing method as "a general principle of EU law" and indicates how it should be applied in judicial and other practice. ${ }^{8}$

Recognition of the central role of the balancing method is closely related to the belief in its infallibility and universality. The method is recognized as a "panacea" suitable for solving a variety of problems. ${ }^{9}$ "The principle of proportionality seeks to provide an objective and accurate answer in the conflict between human rights and public interest, similar to that offered in mathematical equations." ${ }^{10}$

This widespread use of the balancing method and belief in its infallibility is in sharp contradiction with the results of scientific research. Balancing was subjected to intense criticism in the scientific literature. ${ }^{11}$ This criticism demonstrated significant imperfections of the balancing and cast doubt on its suitability of performing its tasks,

\footnotetext{
${ }^{5}$ Regulation (EU) 2016/679, supra note 4, Recital 4.

${ }^{6}$ Regulation (Eu) 2016/679, supra note 4.

7 EDPS Guidelines, supra note 2.

8 Ibid., 8

9 Edward Guntrip, "International Human Rights Law, Investment Arbitration and Proportionality Analysis: Panacea or Pandora's Box?" Blog of the European Journal of International Law (January 7, 2014) // https://www.ejiltalk.org/international-human-rights-law-investment-arbitration-and-proportionalityanalysis-panacea-or-pandoras-box/; Alexey V. Dolzhikov, "The European Court of Human Rights on the Principle of Proportionality in 'Russian' Cases," Teise 82 (2012): 217-218; Jan Sieckmann, "Proportionality as an Universal Human Rights Principle"; in: David Duarteand Jorge and Silva Sampaio, eds., Proportionality in Law. An Analytical Perspective (Cham: Springer, 2018); Erich Vranes, "Vom 'rechten $M a \beta^{\prime} \quad z u m$ globalen Rechtsgrundsatz? Schlaglichter in der Entwicklung des Verhältnismäßigkeitsgrundsatzes" (From 'right measure' to global legal principle? Highlights in the development of the principle of proportionality); in: Günter Herzig, et al., eds., Europarecht und Rechtstheorie (Wien: Verlag Österreich, 2017).

10 Panagiotis Souliotis, supra note 2: 19.

11 Nikiforos Panagis, "Putting Balancing in the Balance" (2014) //

https://tsakyrakis.wordpress.com/2014/03/20/nikiforos-panagis-putting-balancing-in-the-balance/;

Grégoire C. N. Webber, "Proportionality, Balancing, and the Cult of Constitutional Rights Scholarship," Canadian Journal Of Law And Jurisprudence 23 (2010): 180; Ariel L. Bendor and Tal Sela, "How proportional is proportionality?" International Journal of Constitutional Law 13 (2015); Timothy Endicott, "Proportionality and Incommensurability": 311; in: Grant Huscroft, Bradley W. Miller, and Gregoire Webber, eds., Proportionality and the Rule of Law: Rights, Justification, Reasoning (Cambridge University Press, 2014); Francisco J. Urbina, A Critique of Proportionality and balancing (Cambridge: Cambridge University Press, 2017); Stavros Tsakyrakis, "Proportionality: An Assault on Human Rights?" Jean Monnet Working Paper 09/08 (2009) // https://jeanmonnetprogram.org/paper/proportionality-an-assault-onhuman-rights-2/; Julian Rivers, "Proportionality and Variable Intensity of Review," The Cambridge Law Journal 65 (2006): 175.
} 
concluding that "the principle of proportionality concerning human rights cases should - at least - be questioned, or even jettisoned."12

The most surprising thing is that the use of the balancing method tends to ignore all of this criticism. The European Court of Human Rights, the legislators of the European Union, the European Commission - they all widely use the balancing method and make crucial decisions without discussing limitations of balancing and drawbacks of decisions made on its basis. Many improvements to the balancing method proposed in the scientific literature are ignored and are not taken into account when considering court cases or making other decisions. ${ }^{13}$

This article discusses the scope of this phenomenon, its manifestations, and its impact on the quality of data protection decisions based on the balancing method, the implications of this situation for the current state, and further development of personal data protection in the European Union.

The article consists of an introduction and four parts. The first part summarizes the modern criticism of the balancing method and identified disadvantages and limitations. The second part examines the practical application of the balancing method and shows that practice ignores its shortcomings and limitations, which this criticism points to. The third part shows the consequences of this disregard for decisions based on the balancing method. The fourth part discusses how to ensure that the shortcomings and limitations of the balancing method are taken into account when making practical decisions.

\section{CURRENT CRITICISM OF THE BALANCING METHOD}

For balancing to be successful, that is, to determine the optimal relationship between competing rights, it must meet specific requirements. John Fennis has summarized the basic requirements for the balancing method. According to him, the outcome of balancing hinges on whether "(1) goals are well-defined, (2) costs can be compared by references to some definite unit of value (for example money), (3) benefits too can be quantified in a way that renders them commensurable with one another, and (4) differences among the means, other than their measurable costs,

\footnotetext{
12 Panagiotis Souliotis, supra note 2" 19

13 Laura Clerico, "Proportionality in Social Rights Adjudication: Making it Workable"; in: David Duarteand and Jorge Silva Sampaio, eds., Proportionality in Law. An Analytical Perspective (Cham: Springer, 2018); Giovanni Sartor, "Consistency in Balancing: From Value Assessments to Factor-Based Rules"; in: David Duarte and Jorge Silva Sampaio, eds., Proportionality in Law. An Analytical Perspective (Cham: Springer, 2018); Giovanni Sartor, "The right to be forgotten: balancing interests in the flux of time," International Journal of Law and Information Technology 24 (2016): 75-91; Giovanni Sartor, "The Logic of Proportionality: Reasoning with Non-Numerical Magnitudes," German Law Journal 14:8 (2013): 1419; Jochen von Bernstorff, "Proportionality without Balancing. Comparative Judicial Engagement": 63; in: Liora Lazarus, et al., eds., Reasoning Rights (Oxford/Portland: Hart Publishing, 2014).
} 
measurable benefits, and other aspects of their respective efficiency as means, are not counted as significant." ${ }^{14}$

In this way:

1) the rights being compared must be commensurable;

2) these rights (and other terms used in balancing) must be clearly defined;

3) the balancing procedure must ensure its accuracy and objectivity.

The criticism of balancing casts doubts on the correspondence of the method to all these requirements.

\subsection{INCOMMENSURABILITY: THE PROBLEM OF A COMMON MEASURE}

The purpose of balancing is to determine which of the two competing rights "weighs more." This supposes that every competing right has certain "weight", and it is necessary to "measure" it and to determine which right "weighs" more and how much more. This will allow harmonizing these rights according to these "weights". Thus, balancing can only be done if both rights can be measured. These measures can be compared. ${ }^{15}$

The need to establish such a common measure is beyond any doubt: "If there is no rational basis for deciding one way rather than the other, then the result seems to represent a departure from the rule of law, in favour of arbitrary rule by judges."16

However, the implementation of this requirement runs into significant difficulties.

\section{Human rights are immeasurable.}

We do not have any reliable measure to measure the "weight" (e.g., percentage, or score) of a particular human right. ${ }^{17}$ However, if the weight of any right cannot be measured, it cannot be weighed, and if it cannot be weighed, it cannot be balanced.

2. Weights of different rights may not be comparable.

Even if both rights can be measured, that is still not enough to compare them. A common measure is necessary. "The requirement for proportionality sensu stricto

\footnotetext{
14 John Finnis, "Commensuration and Public Reason": 219; in: Ruth Chang's, eds., Incommensurability, Incompatibility, and Practical Reason (Cambridge: Harvard University Press, 1997).

15 David Wiggins attempts to provide a more precise definition of such a measure: "Option $A$ is commensurable with option B if and only if there is a valuation measure of more and less, and some however complex property $\mathrm{P}$ that is correlative with choice and rationally antecedent to choice and rationally determinant of choice, such that $A$ and $B$ can be exhaustively compared by the said measure in respect of being more $\mathrm{P}$ and less $\mathrm{P}$; where an exhaustive comparison in respect of $\mathrm{P}$-ness is a comparison in respect of everything that matters about either A or B" (David Wiggins, "Incommensurability: Four Proposals"; in: Ruth Chang's, eds. Incommensurability, Incompatibility, and Practical Reason (Cambridge: Harvard University Press, 1997); Madhav Khosla, "Proportionality: An Assault on Human Rights? A Reply," International Journal of Constitutional Law 8 (2010): 302.

16 Timothy Endicott, supra note 11: 311.

17 Ronald Dworkin, "It is absurd to calculate human rights according to a cost-benefit analysis," The Guardian (May 24, 2006): 9.
} 
leads to a problem of incommensurability because it calls for comparing the benefit of a certain restriction of a right with the damage caused by this restriction. But how is it possible, for example, to compare the benefit to the security of the State with the harm to freedom of expression?"18

\section{The identity of the common measure in assessing each of the rights}

Even if a common measure is available, its meaning may be different for each of the rights being compared. This problem is especially crucial from a practical point of view, as it is most closely related to the everyday practice of courts. ${ }^{19}$ By balancing, courts often compare rights in terms of their "significance", "urgency", etc.

Judge of the Australian Supreme Court and renowned legal theorist Aharon Barak describes how a typical judge balances human rights with the public interest:

When the public interest is on one side of the balance ... and on the other side we find a constitutional right ... the comparison is between the marginal social importance of the benefits gained by advancing the public interest and the marginal social importance of the benefits gained by preventing the harm to the constitutional right. ... This contextual presentation of the issue provides the common denominator-the relative social importance - required to conduct the balance. ${ }^{20}$

As seen from the above description, this "relative social importance" is supposed to be a universal and straightforward common measure balancing all possible human rights. However, this simplicity and universality are illusory. In reality, the meaning of relative social significance can be very different for each of the compared rights. As Timothy Endicott has put it: "Identifying a single criterion does not eliminate incommensurability if the application of the criterion depends on considerations that are themselves incommensurable ... In human rights cases, the availability of the covering value, 'importance', does not give us any reason to think that the grounds on which judgments are to be made are commensurable"21. In other words, despite the existence of a general measure, the rights can still be incomparable because when assessing the relative importance of each of the compared rights, the judge may have various considerations. Moreover, these considerations may vary from one judge to another. "Balancing seemingly permits judges enormous latitude in measuring values and facts for inclusion on the scales

\footnotetext{
18 Ariel L. Bendor and Tal Sela, supra note 11: 541.

19 Jorge Silva Sampaio, "Proportionality in its Narrow Sense and Measuring the Intensity of Restrictions on Fundamental Rights"; in: David Duarte and Jorge Silva Sampaio, eds., Proportionality in Law. An Analytical Perspective (Cham: Springer, 2018).

20 Aharon Barak, Proportionality. Constitutional Rights and their Limitations (Harvard: Cambridge University Press, 2012), 483-484.

21 Timothy Endicott, supra note 11: 311-312.
} 
while, at the same time, purporting to be objective, neutral, and even scientific." 22 The consequence is the inaccuracy of the balancing results- "any decision balancing two values that do not share a common basis is subjective and based on intuition"23.

All this means that the use of the balancing method cannot be based on the presumption that it is always accurate, has no limitations, and that the decision taken on that basis is therefore impeccable. Thus, the first task encountered in balancing competing rights is to establish an appropriate common measure. It requires that both competing rights be: 1) measurable, 2) comparable, 3) a common measure would have the same meaning for both. If there is any doubt about this, it is necessary to:

1. Take into account that the balancing may be inaccurate or wrong.

2. Assess the likely degree of this inaccuracy. If this possible inaccuracy goes beyond a specific limit, the balancing has to be rejected.

3. If this potential inaccuracy nevertheless remains within the permitted limits, the possible consequences of this inaccuracy should be considered. It is necessary to identify situations in which this inaccuracy can lead to undesirable consequences and outline appropriate preventive measures.

\subsection{LACK OF PRECISE DEFINITION OF COMPETING RIGHTS AND TERMS USED IN THE BALANCING PROCESS}

When weighing we need to know what we put on the scales. Likewise, the precondition for a successful weighing of rights is an accurate knowledge of what is being weighed and what the exact content of each of these rights is.

The lack of such definitions is the second area of criticism. The point is that the content of human rights (freedom, human dignity, etc.) is very diverse. The understanding of these rights depends primarily on the epoch, country, person. The infinite flexibility of these concepts has allowed even the most totalitarian regimes to proclaim that they are fighting for "true" freedom and "true" human dignity by adding to these concepts the content that the totalitarian regime needs. Significant differences exist between the definitions found in scientific publications ("reasonable", "pressing social needs", etc). ${ }^{24}$

\footnotetext{
22 David L. Faigman, "Madisonian Balancing: A Theory of Constitutional Adjudication," Northwestern University Law Review 88 (1994): 648.

${ }^{23}$ Ariel L. Bendor and Tal Sela, supra note 11: 542.

24 Jack Donnelly, Universal Human Rights in Theory and Practice (New York: Cornelian University Press, 2013), 109; David Boersema, Philosophy of Human Rights: Theory and Practice (New York: Routledge, 2018), 48; Juan Cianciardo, "The principle of proportionality: the challenges of human rights," Journal of Civil Law Studies 3:1 (2010): 180; Luka Anđelković, "The Elements of Proportionality as a Principle of Human Rights Limitations," Facta Universitatis Series: Law and Politics 15:3 (2017): 237.
} 
Other terms used in balancing also are just as challenging to define: "The method of practical reasonableness promoted by proportionality and balancing brings with it a vocabulary all its own, including "interest," "value," "cost," "benefit," "weight," "sufficient," and "adequate." The concepts of "good" (and "bad"), "right" (and "wrong"), "correct" (and "incorrect") are absent, as is the conceptual clarity associated with this vocabulary." 25

There are particular problems in balancing the right to data protection with the so-called "public interest", and in trying to clarify this concept. "However, ambiguity surrounds the meaning and the scope of the notion of public interest mainly because that there are many different theories about its exact concept." 26

A contributing factor for the vagueness of the concept is also the false impression that the public interest is the interest of the majority. To put it differently, some argue that we can locate the public interest if we take a simple look at what the elected representatives of the people have voted for. An indication of this belief has influenced even the Court when it considered that the position of the majority $(87 \%)$ of Tyroleans not to be offended by the film expressed the public interest, especially if we take into account the phrase that the Roman Catholic religion is the religion of the overwhelming majority of Tyrolese. ${ }^{27}$

All this leads to the same conclusions about the balancing method and its application in practice. It is necessary to acknowledge that significant inaccuracy of its results is possible, that this inaccuracy can have an equally significant impact on the decision based on balancing, and that ignoring this inaccuracy of balancing and of the decision made on its basis can lead to the most undesirable consequences.

\subsection{ACCURATE AND OBJECTIVE WEIGHING PROCEDURES}

Accurate balancing requires not only a common measure and well-defined concepts but also a precise weighing procedure. Weighing actions must be clearly defined, transparent, and their result must be the same, regardless of the psychological traits, tastes, and interests of the judge or other person performing the weighing. The uncertainty of the balancing procedure and the resulting subjectivism is the third area of criticism of balancing. ${ }^{28}$

The point is that scales, where the competing rights are weighed, do not exist in reality. They are replaced by the judge's imagination, which occupies a central place in the weighing procedure. During the weighing, the judge or other balancing

\footnotetext{
25 Grégoire C. N. Webber, supra note 11: 180.

26 Panagiotis Souliotis, supra note 2: 7.

27 Ibid.

28 Sué González Hauck, "A Critique of Proportionality Balancing as a Harmonization Technique in International Law," Völkerrechtsblog (5 August 2015): 1 // DOI: 10.17176/20170920-12125.
} 
person tries to imagine both rights and asks himself the question: "Which one is more significant?" The answer to this question depends largely on how he imagines the rights being weighed and where he sees the sources of their importance. Furthermore, this, in turn, depends on his personal experience, personal characteristics, social situation, on what he sees in everyday life, what he hears and sees on TV, in conversations with family, colleagues, and friends.

Here is how long-time U.S. Supreme Court Justice Richard Posner describes the mental processes that occur in the mind of a judge when he juxtaposes rights:

The weighting is the result of a complicated interaction-mysterious, personal to every judge-of modes of reasoning (analysis, intuition, emotion, common sense, judgment), political and ideological inclinations, personality traits, other personal characteristics, personal and professional experiences, and the constraints implicit in the rules of the judicial "game". ${ }^{29}$

Describing the practical reasoning of a judge, based on which balancing is performed, the same author notes: the practical reasoning of a judge is "a grab bag that includes anecdote, introspection, imagination, common sense, empathy, imputation of motives, speaker's authority, metaphor, analogy, precedent, custom, memory, 'experience,' intuition, and induction (the expectation of regularities, a disposition related both to intuition and to analogy). ${ }^{30}$ Because of this, it is usually not easy to tell how fair the balancing is. "Indeed, how the principle of proportionality generates particular conclusions is difficult to discern, concluding whether legislation "strikes the right balance" or is "proportionate" concerning constitutional rights is, for the most part, asserted rather than demonstrated"31.

Again, this leads to the conclusion that we cannot blindly believe in the objectivity of the balancing procedure and uncritically assume that the balancing procedure always ensures the objectivity and accuracy of its result. Instead, the extent to which the method can ensure an objective and accurate result in each case needs to be assessed and taken into account when making the decision.

\section{THE EXTENT TO WHICH THE DISADVANTAGES AND LIMITATIONS OF} THE BALANCING METHOD ARE TAKEN INTO ACCOUNT IN PRACTICE

No ship will start its voyage as long as there are doubts about the accuracy of the compass. Furthermore, if the compass is inaccurate but there is no other, the captain must determine how inaccurate is his only compass. After he finds out the degree of inaccuracy of his compass, the captain should think about the problems

\footnotetext{
29 Richard Posner, How Judges Think (Cambridge: Harvard University Press, 2008), $116-117$.

30 Richard Posner, The Problems of Jurisprudence (Cambridge: Harvard University Press, 1990$), 73$.

31 Grégoire C. N. Webber, supra note 11: 180.
} 
that may arise along the way due to this inaccuracy. He should also outline measures that need to be taken in order to prevent the undesirable consequences of the inaccuracy of his compass.

Balancing is a crucial compass in finding the most accurate solution to conflicts between competing rights. As a result, in every single case, the "masters" of these decisions (judge, legislator, law enforcer) have to imagine exactly how accurate their compass - i.e. their balancing method - is, when it may be inaccurate, what problems may arise due to its inaccuracies, and how to clarify and solve these problems in time. Do they have the proper tools for all that?

The answer to this question should be found primarily in the official "EDPS Guidelines on assessing the proportionality of measures that limit the fundamental rights to privacy and to the protection of personal data," which indicates how the balancing method should be applied in the European Union. ${ }^{32}$ This document is intended for anyone who applies the balancing method and, above all, to legislators, courts, national supervisory authorities, and just people who use balancing in their daily activities. This document is intended to summarize the best practices of balancing in the world and, especially in the EU, integrate it with the achievements of modern science and on this basis to formulate recommendations on how balancing should be implemented.

The great importance of this document is connected, first of all, with the authority of the European Commission. The publisher of this document, the EDPS (European Data Protection Supervisor), is a body of the European Commission that: monitors and ensures the protection of personal data and privacy when EU institutions and bodies process the personal information of individuals; advises EU institutions and bodies on all matters relating to the processing of personal data, on request or on our own initiative, is consulted by the European Commission on proposals for legislation, international agreements, as well as implementing and delegated acts with impact on data protection and privacy; intervenes before the Court of Justice of the EU to provide expert advice on interpreting data protection law. ${ }^{33}$

To what extent does this important document take into account the disadvantages and limitations of the balancing method discussed above?

32 EDPS Guidelines, supra note 2.

33 European Data Protection Supervisor, "About" (2018) //https://edps.europa.eu/about-edps_en. 


\subsection{SHOULD THIS DOCUMENT TAKE INTO ACCOUNT CRITICS' OPINIONS AND THE FLAWS AND LIMITATIONS OF THE BALANCING METHOD INDICATED BY IT?}

The limitations of the balancing method typically are not discussed and are not taken into account when considering legal cases and solving practical issues. Therefore, it is assumed that the shortcomings and limitations of the balancing method, which the criticism pointed out, are irrelevant when making real-life decisions. Therefore, the question arises: Is this tacit assumption true? Maybe the judge indeed has the right to be unaware of this criticism and, in their practical activities, ignore the conclusions of the researchers?

Scientific discussion and critique are a common and normal phenomenon in science when it explores new things and seeks solutions to new problems. Scientific discussion, firstly, helps to identify commonly recognized statements that are no longer in doubt and on which we can rely making practical decisions. Second, this discussion helps to identify statements that are still under discussion. In this case, on the contrary, people involved in some practical activity should know that they cannot unconditionally rely on them. On the contrary, they should carefully consider the criticism of these provisions and decide how it should be taken into account when making specific decisions. In particular, in the case of balancing, it means that in every single case, they should clarify how the shortcomings of balancing may impact the accuracy of balancing and efficiency of decisions made on its basis.

Therefore, a guidance document on the practical application of the balancing method should give recommendations on how to solve the problems associated with the inaccuracy of the balancing method in practice.

In particular, the following questions should be answered:

- How to establish whether there is a common measure necessary for juxtaposing two rights?

- $\quad$ Are the concepts on which balancing will be based clearly defined?

- Is the balancing procedure transparent and clear?

- What degree of accuracy is required to make this decision, and does the existing common measure, concepts, and balancing procedure provide it?

- What are the limitations of this balancing, and how to take them into account? 


\subsection{THE PROBLEM OF A COMMON MEASURE}

Do the "EDPS Guidelines" discuss weaknesses and limitations of the balancing method to which criticism pointed? Are recommendations made on how to take into account these shortcomings and limitations in each case? Is it explained how to check if the rights are comparable?

The answer to all these questions is "no". Balancing sensu stricto is addressed in "EDPS Guidelines ..." part III "Checklist for assessing the proportionality of new legislative measures". ${ }^{34}$ Here are questions to be answered by the judge or other balancing person. ${ }^{35}$

None of these questions is about the limitations and shortcomings of the balancing method. The issue is not discussed and recommendations are not given as to how to identify the possible impact of the above deficiencies and limitations of the accuracy of balancing, and how to establish their impact on the quality of the decision made on the basis of balancing?

The "EDPS Guidelines" also provides several examples of court decisions that relied on balancing. However, none of them discusses the above-mentioned problems, although they inevitably arise with each balancing. ${ }^{36}$

\subsection{UNCERTAINTY OF TERMS USED IN THE BALANCING PROCESS}

The uncertainty of concepts is an important obstacle to successful balancing and has become a source of intense criticism. This problem arises in every case when the balancing method is used. Naturally, the "EDPS guidelines" should discuss this problem and give instructions on how to solve it.

However, this problem is also not discussed. It is assumed that if any clarification of the concept is necessary, the court must do so. For example, if, in a privacy case, the court finds that the content of the term "right to privacy" is not explicit enough, it is for the court to clarify the content of that concept and then to decide the case on that basis. After this decision, the party who has understood this concept differently than the court loses the lawsuit. Thus, an individual who applies a legal norm is obliged to predict in advance the opinion of a future court on how this norm should be applied. Thus, it proceeds from the position that the law enforcer has the ability of a prophet and can predict the court decision. However, in reality, this task often exceeds a person's real potential. How can a person predict a future court

${ }^{34}$ EDPS Guidelines, supra note 2, 12-32.

35"Are we in the presence of a pressing social need for restricting the right (to privacy and/or data protection)?", "Does the envisaged purpose correspond to this need?", "Does the measure, taking into account its impact/consequences, solve the problem?". "Assess the importance of the objective (is it to protect a constitutional value or a fundamental right?" (EDPS Guidelines, supra note 2,16, 17).

36 EDPS Guidelines, supra note 2, 18-19, 25-26,29-34. 
decision if this issue is the subject of fierce judicial debates and can then be changed several times in the higher courts?

All this creates a situation where, when making a specific decision, a person does not have a precise idea of the scope of his rights, as this scope will be clarified only in the future. ${ }^{37}$ "It is likewise impossible to know exactly which rights we have at any given moment." 38

To avoid this problem: well-defined concepts should be provided; in the absence of such a concept, a precise procedure must be provided, which would show what measures the judge should take to clarify the uncertain concept as much as possible; and, if the concept so clarified later is nevertheless in doubt and the judge is blamed for having defined a particular concept incorrectly, then he should only be required to provide evidence that he wholeheartedly followed the above procedure to clarify such a concept as much as possible. If he can demonstrate it, he cannot be held liable for the fact that his understanding of this concept is different from that which the court later recognized as correct.

\subsection{DECISION PROCEDURE: ITS OBJECTIVITY}

An important direction of the critique of balancing is the subjectivity of the weighing procedure. We have seen that such subjectivity broadly opens the door to various considerations dictated by political, economic, social, and other interests and preferences. In response to this criticism, the "EDPS Guidelines" should have provided up-to-date science-based advice on how to reduce the subjectivity of such balancing.

The achievements of modern science certainly provide such opportunities. The intuition of the judge, the legislature, and other practitioners of law has become the subject of intensive research. The important role of the lawyer's incomprehensible (subconscious) intuitive thinking in these decisions has been demonstrated, how such intuitive decisions are made are investigated and described (heuristics), methods that allow improving such solutions, and avoiding their subjectivity, are proposed, and their effectiveness is proved. ${ }^{39}$ However, the "EDPS Guidelines" do not discuss them and do not give any recommendations on their use.

\footnotetext{
37 Pedro Monis Lopes, "Balancing Principles and a Forteriori Reasoning"; in: David Duarte and Jorge Silva Sampaio, eds., Proportionality in Law. An Analytical Perspective (Cham: Springer, 2018).

38 Stijn Smet, "On the Existence and Nature of Conflicts between Human Rights at the European Court of Human Rights," Human Rights Law Review 9:1 (July 2017): 9 // DOI: https://doi.org/10.1093/hrlr/ngx016; Joel Feinberg, "Voluntary Euthanasia and the Inalienable Right to Life," Philosophy \& Public Affairs 93 (1978): 231.

39 Eyal Peer and Eyal Gamliel, "Heuristics and Biases in Judicial Decisions," Court Review 49 (2013); Emma Bienias, et al., "Implicit bias in the legal profession" (2017) // https://ipo.org/wpcontent/uploads/2017/11/Implicit-Bias-White-Paper-2.pdf; Kathleen Nalty, "Strategies for Confronting Unconscious Bias," The Federal Lawyer (January/February 2017).
} 
Thus, the "EDPS Guidelines" gives guidance on how to apply the balancing method without discussing the shortcomings and limitations of the method, to which its criticism points. In this way, we observe a unique situation. Balancing research and its practice live separately from each other. The practice does not "hear" scientific criticism. The judge or lawmaker simply leaves out of sight scientific publications that point out the shortcomings of the balancing method. Instead, they continue to use the balancing method implicitly based on the assumption that the flaws indicated by the criticism are not relevant to the practical application of the method.

Of course, this resistance to the application of a scientific approach to practice is largely associated with problems arising from the differences in scientific and practical thinking (that are also faced by law). Due to these problems, the transfer of scientific knowledge into the sphere of practical activity always runs into significant methodological issues, which becomes a source of resistance to its use.

However, the phenomenon of ignoring scientific criticism by practice arises from the historically established relationships between scientific research in the field of law and its practice. Perhaps this lack of attention to criticism of the balancing method stems primarily from a general idea that "everyone should do his own thing". The judge should judge and not interfere with the researcher, and the researcher, in turn, should also do his job and not interfere with the judge. Another possible reason is that critics point out the flaws of the balancing method, without answering the question: "so what to do?" In this case, criticism is not addressed because nothing better is offered.

It is true that until a balancing method, free of all the indicated drawbacks and limitations, is proposed, one has to use the one available. However, perfect methods generally do not exist at all. Any tool has its drawbacks and limitations. Therefore, a good master does everything to use the strengths of his instrument and at the same time takes into account its shortcomings. The guidelines of any method should do the same: they should indicate not only how to apply the method, but also discuss its limitations and disadvantages and how to take them into account when using the method.

\section{CONSEQUENCES}

The practice of applying the balancing method tends to ignore the shortcomings and limitations of the method, which its criticism points to. What are the consequences of this unique situation? 


\subsection{SUB-OPTIMAL DECISIONS}

The main goal of balancing is to ensure an optimal relationship between competing rights (including personal and other people's rights). However, balancing, which is performed with an inaccurate measure, using inaccurate concepts and following an inaccurate procedure, may be very far from optimal. The consequence of this is ineffective legal regulation, wasted financial and other resources, unrealized rights. For example, available economic studies on privacy regulation show that decisions in this area are linked to astronomical differences in the cost of the privacy system. ${ }^{40}$

\subsection{DISSATISFACTION WITH THE LEGAL REGULATION}

The optimal balancing could ensure the optimal use of available resources and, consequently, the optimal satisfaction of users. In the case of sub-optimal balancing, resources are used inefficiently, and this causes dissatisfaction. The consequences of such dissatisfaction are well-studied and described in publications on the psychology of legitimacy. ${ }^{41}$

The most critical consequences are as follows:

- The authority of such regulation is low. Unpopular law does not enjoy authority. People willingly acknowledge, respect, and comply with popular law. They are reluctant to recognize and perform an unpopular one. What follows, such unpopular regulation only works in the presence of constant control of its implementation and severe sanctions for non-compliance.

- Instability of such regulation. The law works if it is stable. If the law is stable, then over time, its observance becomes habitual. People follow it because they are used to doing what this law requires. In contrast, the unpopular law is unstable. Such frustrating legislation causes constant criticism and resistance. Everyone is unhappy with it, and the general opinion about it is that it is imperfect and needs to be improved. All this brings an endless chain of amendments to such a law and what follows, its instability. Therefore, following it does not become habitual.

\footnotetext{
40 Nicholas Blades and Fernando Herrera-González, "An economic analysis of personal data protection obligations in the European Union," European Regional Conference of the International Telecommunications Society (ITS), Cambridge, United Kingdom (7-9 September 2016) // https://aisel.aisnet.org/icis2018/economics/Presentations/; Nicole Lindsey, "Understanding the GDPR Cost of Continuous Compliance" (2019) // https://www.cpomagazine.com/data-protection/understandingthe-gdpr-cost-of-continuous-compliance/; Tim Worstall, "Is GDPR worth the cost?" (2018) // https://www.computerweekly.com/opinion/Is-GDPR-worth-the-cost; Elina Pyykkö, "Data protection at the cost of economic growth?" (2012) // https://www.ceps.eu/ceps-publications/data-protection-costeconomic-growth/; David Duarte, "Gains and Losses in Balancing Social Rights"; in: David Duarte and Jorge Silva Sampaio, eds., Proportionality in Law. An Analytical Perspective (Cham: Springer, 2018).

41 Tyler Tom, "Psychological Perspectives on Legitimacy and Legitimation," Annual Review of Psychology 57 (2006).
} 
- The formation of a culture of non-compliance. Such a law is perceived mainly as a hindrance in everyday life. When dealing with such a law, people think not about how to implement it, but about how to get around it. A culture of "circumvention" of such unpopular legal regulation develops.

\subsection{THE OPACITY OF BALANCING SOLUTIONS}

We have seen above that the intuitive weighing of competing rights plays a crucial role in the balancing procedure. The main feature of such an intuitive solution is its opacity. In the case of an intuitive decision, the judge or another person performing balancing is far from always be able to clearly and consistently, step by step expound, why he has given more weight to some considerations and less to others. The fact is that in the case of an intuitive decision, the person simply "feels", he has an "inner conviction" that a particular decision is right. ${ }^{42}$

All this is true in the case of balancing. It is not always possible for a judge or practitioner to give a sufficiently clear answer as to why, in deciding, he has given more weight to some considerations and less to others. The consequence is the opacity of the balancing process. Another person cannot see the full sequence of the balancer's thoughts that led him to a particular decision. As a result, he does not have the opportunity to make sure that this solution is optimal. He may feel that in this case he would have made a completely different decision. The main consequence of this lack of transparency is that balancing rights quickly turns into a simple struggle between the parties for their interests, in which the winner is not the right one, but the stronger one.

Behind any conflict of rights lie the different interests of people or groups of people. However, balancing by its very essence, satisfies the needs of each party only to a certain extent. Reconciling opposing rights always implies only partial satisfaction of the interests of each party. All this means that both parties remain to some degree, dissatisfied, which gives rise to a desire to influence the course of balancing. Uncertainty, secrecy, and the subjectivity of the balancing procedure resulting from them open up scope for hidden influence on the judge or other person who carries out the balancing. Both parties can have a desire to influence the balancing process behind the scenes. As a result, balancing becomes the scene of a struggle of interests, where the winner is not the right one, but the one who has more opportunities for covert influence on the balancing process. The outcome of such balancing no longer depends on legal principles and procedures but the balance of power between the parties.

42 Daniel Kahneman, Thinking Fast and Slow (New York: Farrar, Straus and Giroux, 2011), 216-218. 
Thus, the application of the balancing method without taking into account its shortcomings and limitations does not ensure optimal coordination of rights generates dissatisfaction with legal regulation, a constant tendency to reform it, and forms a "culture of circumvention" of this regulation.

All this leads to a decrease in the authority and popularity of the privacy right. It becomes a right that is "too expensive," which does not help but interferes with one's interests.

\section{WHAT TO DO}

1. The shortcomings and limitations of the balancing method identified by criticism are not only theoretical but also practical problems that every balancing case encounters.

2. Guidelines and other documents that guide the application of the balancing method in practice should also discuss the shortcomings and limitations of the balancing method and give recommendations on how to take them into account when using the method in real practice in solving everyday problems.

3. For each application of the balancing method (consideration of court cases, improvement of legislation, application of legal norms governing privacy), problems associated with the use of the balancing method in this case, and how these problems were resolved should be discussed.

\section{CONCLUSIONS}

1. The balancing method is widely used to deliver critical judicial, legislative, and other decisions. However, as widespread criticism of this method shows, its reliability is, at least, questionable. It is due to: the lack of reliable criteria for comparing competing rights (the problem of a common measure); difficulties in determining the concepts used; and the lack of a proper and transparent procedure. As a result, when applying the method, there is no guarantee that the correlation between competing rights established with its help is the best possible. Therefore, when using the method, the main questions remain unanswered: to what extent have the flaws and limitations of the balancing identified by critics affected its results? And, can these results become the basis for a correct ratio of competing rights?

2. When applying the balancing method in practice, in making judicial, legislative, and other decisions, there is a trend of ignoring the shortcomings and limitations of this method identified by the critic. The question of possible errors and inaccuracies that may be caused by the weaknesses and limitations of this method are not usually considered. When using the balancing method, the judge or the 
legislator does not try to find out whether the indicated prerequisites for balancing (general measure, exact concepts, proper and transparent procedure) exist and, accordingly, to what extent and with what reservations balancing can be applied and trusted in the case.

3. Ignoring the criticisms of the weaknesses and limitations of the balancing method has far-reaching consequences:

a) suboptimal decisions on the due relationship of competing rights;

b) discontent and distrust of those who follow legislative, judicial, and other choices based on balancing;

c) a constant demand for reform of such laws;

d) its instability;

e) the decisive role of subjective factors in balancing.

4. The reasons for the phenomenon of neglect are associated with general problems arising from the differences in scientific and practical knowledge in general, particularly in the field of law. Due to these problems, the transfer of scientific knowledge into the sphere of legal activity is always associated with numerous methodological issues. In addition, this phenomenon stems from historically established features of the relationship between the scientific study of law and its practical application.

5. The inability of balancing practices to take into account weaknesses and limitations revealed by criticism is associated with the inadequacy of mechanisms that transform scientific knowledge (in this case, on the shortcomings and limitations of the balancing method) into a practical one. The role of the "bridge" between these types of knowledge should be carried out by methodological documents that should assist practitioners in identifying and solving problems that arise when converting scientific knowledge into practical actions. In the field of ensuring the right to privacy, such a role should be fulfilled by the "EDPS Guidelines on assessing the proportionality of measures that limit the fundamental rights to privacy and the protection of personal data". However, as the material examined by us shows, so far, this publication does not fulfil this mission. Instead, the EDPS and its guidelines follow the common practice of ignoring the results of scientific research.

6 . The first step in solving these problems should be the recognition of the need to take into account the shortcomings and limitations of the balancing method identified by criticism, both when making individual legislative, judicial, and other decisions and determining the general methodological requirements for the application of the balancing method. 


\section{BIBLIOGRAPHY}

1. Anđelković, Luka. "The Elements of Proportionality as a Principle of Human Rights Limitations." Facta Universitatis Series: Law and Politics 15:3 (2017): 235 - 244.

2. Barak, Aharon. Proportionality. Constitutional Rights and their Limitations. Harvard: Cambridge University Press, 2012.

3. Bendor, Ariel L., and Tal Sela. "How proportional is proportionality?" International Journal of Constitutional Law 13 (2015): 530-544.

4. Bernstorff, Jochen von. "Proportionality without Balancing. Comparative Judicial Engagement": 63-83. In: Liora Lazarus, et al., eds. Reasoning Rights. Oxford/Portland: Hart Publishing, 2014.

5. Bienias, Emma, et al. "Implicit bias in the legal profession" (2017) // https://ipo.org/wp-content/uploads/2017/11/Implicit-Bias-White-Paper-2.pdf.

6. Blades, Nicholas, and Fernando Herrera-González. "An economic analysis of personal data protection obligations in the European Union." $7^{\text {th }}$ European Regional Conference of the International Telecommunications Society (ITS). Cambridge, United Kingdom (7-9 September 2016) // https://aisel.aisnet.org/icis2018/economics/Presentations/.

7. Boersema, David. Philosophy of Human Rights: Theory and Practice. New York: Routledge, 2018.

8. Burazin, Luka. "Conflicts Between Fundamental Rights Norms": 111-120. In: David Duarte and Jorge Silva Sampaio, eds. Proportionality in Law. An Analytical Perspective. Cham: Springer, 2018.

9. Cianciardo, Juan. "The principle of proportionality: the challenges of human rights." Journal of Civil Law Studies 3:1 (2010): 177-185.

10. Clerico, Laura. "Proportionality in Social Rights Adjudication: Making it Workable": 25-48. In: David Duarte and Jorge Silva Sampaio, eds. Proportionality in Law. An Analytical Perspective. Cham: Springer, 2018.

11. Dolzhikov, Alexey V. "The European Court of Human Rights on the Principle of Proportionality in 'Russian' Cases." Teisè 82 (2012): 215-224.

12. Donnelly, Jack. Universal Human Rights in Theory and Practice. New York: Cornelian University Press, 2013.

13. Duarte, David. "Gains and Losses in Balancing Social Rights": 49-70. In: David Duarte and Jorge Silva Sampaio, eds. Proportionality in Law. An Analytical Perspective. Cham: Springer, 2018.

14. Dworkin, Ronald. "It is absurd to calculate human rights according to a costbenefit analysis." The Guardian (May24, 2006). 
15. Endicott, Timothy. "Proportionality and Incommensurability": 311-342. In: Grant Huscroft, Bradley W. Miller, and Gregoire Webber, eds. Proportionality and the Rule of Law: Rights, Justification, Reasoning. Harvard: Cambridge University Press, 2014.

16. European Data Protection Supervisor. "About" (2018) // https://edps.europa.eu/about-edps_en.

17. Faigman, David L. "Madisonian Balancing: A Theory of Constitutional Adjudication." Northwester University Law Review 88 (1994): 641-694.

18. Feinberg, Joel. "Voluntary Euthanasia and the Inalienable Right to Life." Philosophy \& Public Affairs 93(1978): 223-257.

19. Finnis, John. "Commensuration and Public Reason": 215-260. In: Ruth Chang's, eds. Incommensurability, Incompatibility, and Practical Reason. Cambridge MA: Harvard University Press, 1997.

20. Guntrip, Edward. "International Human Rights Law, Investment Arbitration, and Proportionality Analysis: Panacea or Pandora's Box?" Blog of the European Journal of International Law (January 7, 2014) //

https://www.ejiltalk.org/international-human-rights-law-investmentarbitration-and-proportionality-analysis-panacea-or-pandoras-box/.

21. Hauck, Sué González. "A Critique of Proportionality Balancing as a Harmonization Technique in International Law." Völkerrechtsblog (5 August 2015) //

DOI: $10.17176 / 20170920-12125$.

22. Kahneman, Daniel. Thinking, Fast and Slow. New York: Farrar, Straus and Giroux, 2011.

23. Kelleher, Denis, and Karen Murray. EU Data Protection Law. London: Bloomsbury Publishing, 2018.

24. Khosla, Madhav. "Proportionality: An Assault on Human Rights? A Reply." International Journal of Constitutional Law 8 (2010): 298-306.

25. Lindsey, Nicole. "Understanding the GDPR Cost of Continuous Compliance" (2019) //

https://www.cpomagazine.com/data-protection/understanding-the-gdpr-costof-continuous-compliance/.

26. Lopes, Pedro M. "Balancing Principles and A Forteriori Reasoning": 137-156. In: David Duarte and Jorge Silva Sampaio, eds. Proportionality in Law. An Analytical Perspective. Cham: Springer, 2018.

27. Nalty, Kathleen. "Strategies for Confronting Unconscious Bias." The Federal Lawyer (January/February 2017): 27-34.

28. Panagis, Nikiforos. "Putting Balancing in the Balance" (2014): 1-10 // 
https://tsakyrakis.wordpress.com/2014/03/20/nikiforos-panagis-puttingbalancing-in-the-balance/.

29. Peer, Eyal, and Eyal Gamliel. "Heuristics and Biases in Judicial Decisions." Court Review 49 (2013): 114-118.

30. Posner, Richard. How Judges Think. Cambridge: Harvard University Press, 2008.

31. Posner, Richard. The Problems of Jurisprudence. Cambridge: Harvard University Press, 1990.

32. Pyykkö, Elina. "Data protection at the cost of economic growth?" (2012) // https://www.ceps.eu/ceps-publications/data-protection-cost-economicgrowth/.

33. Rivers, Julian. "Proportionality and Variable Intensity of Review." The Cambridge Law Journal 65:1 (2006): 174-207.

34. Sampaio, Jorge S." Proportionality in its Narrow Sense and Measuring the Intensity of Restrictions on Fundamental Rights": 71-110. In: David Duarte and Jorge Silva Sampaio, eds. Proportionality in Law. An Analytical Perspective. Cham: Springer, 2018.

35. Sartor, Giovanni. "Consistency in Balancing: From Value Assessments to Factor-Based Rules": 121-136. In: David Duarte and Jorge Silva Sampaio, eds. Proportionality in Law. An Analytical Perspective. Cham: Springer, 2018.

36. Sartor, Giovanni. "The Logic of Proportionality: Reasoning with Non-Numerical Magnitudes." German Law Journal 14:8 (2013): 1419-56.

37. Sartor, Giovanni. "The right to be forgotten balancing interests in the flux of time." International Journal of Law and Information Technology 24 (2016): 7298.

38. Schlink, Bernard. "Proportionality": 249-266. In: Michel Rosenfeld and Andras Sajó, eds. The Oxford Handbook of Comparative Constitutional Law. Oxford: Oxford University Press, 2012.

39. Sieckmann, Jan. "Proportionality as a Universal Human Rights Principle": 3-48. In: David Duarteand and Jorge Silva Sampaio, eds. Proportionality in Law. An Analytical Perspective. Cham: Springer, 2018.

40. Souliotis, Panagiotis. "Proportionality and The European Convention on Human Rights: A Critical View" (2016): 1-30 // https://papers.ssrn.com/sol3/papers.cfm?abstract_id=2690366.

41. Stijn Smet, "On the Existence and Nature of Conflicts between Human Rights at the European Court of Human Rights." Human Rights Law Review (2017) // DOI: https://doi.org/10.1093/hrlr/ngx016. 
42. Tsakyrakis, Stavros. "Proportionality: An Assault on Human Rights?" Jean Monnet Working Paper 09/08 (2009) //

https://jeanmonnetprogram.org/paper/proportionality-an-assault-on-humanrights-2.

43. Tyler, Tom. "Psychological Perspectives on Legitimacy and Legitimation." Annual Review of Psychology 57 (2006): 375-400.

44. Urbina, Francisco. A Critique of Proportionality and balancing. Cambridge: Cambridge University Press, 2017.

45. Vranes, Erich. "Vom 'rechten Maß' zum globalen Rechtsgrundsatz? Schlaglichter in der Entwicklung des Verhältnismäßigkeitsgrundsatzes" (From 'right measure' to global legal principle? Highlights in the development of the principle of proportionality): 99-136. In: Günter Herzig, et al., eds. Europarecht und Rechtstheorie. Wien: Verlag Österreich, 2017.

46. Webber, Grégoire C. "Proportionality, Balancing, and the Cult of Constitutional Rights Scholarship." Canadian Journal of Law and Jurisprudence 23 (2010): 179-202.

47. Wiggins, David. "Incommensurability: Four Proposals": 52-60. In: Ruth Chang's, eds. Incommensurability, Incompatibility, and Practical Reason. Cambridge, MA: Harvard University Press, 1997.

48. Worstall, Tim. "Is GDPR worth the cost?" (2018) // https://www.computerweekly.com/opinion/Is-GDPR-worth-the-cost.

\section{LEGAL REFERENCES}

1. EDPS Guidelines on assessing the proportionality of measures that limit the fundamental rights to privacy and to the protection of personal data. European Data Protection Supervisor (19 December 2019) // https://edps.europa.eu/data-protection/our-work/our-work-bytype/guidelines_en.

2. Regulation (EU) $2016 / 679$ of the European Parliament and of the Council of 27 April 2016 On the protection of natural persons with regard to the processing of personal data and on the free movement of such data, and repealing Directive 95/46/EC (General Data Protection Regulation) EU General Data Protection Regulation (EU-GDPR). Official Journal of the European Union L 119/1 2016. 